\title{
Evaluation of the eighth AJCC TNM stage for lung cancer (NSCLC): a meta-analysis of 8 validation studies
}

Durgesh Wankhede ( $\square$ drdurgeshwankhede@gmail.com )

\section{Research}

Keywords: Lung Cancer, NSCLC, Stage, AJCC, TNM classification, meta-analysis

Posted Date: April 8th, 2020

DOI: https://doi.org/10.21203/rs.3.rs-20871/v1

License: (a) (i) This work is licensed under a Creative Commons Attribution 4.0 International License.

Read Full License 


\section{Abstract}

Introduction The AJCC eighth edition TNM classification for lung cancer was released in 2017 and included major newer modifications. External validation studies have evaluated the efficacy of the new system and obtained paradoxical results. Methods A meta-analysis was performed of these studies to evaluate the new classification. Eight eligible studies with 654,185 patients were included in the analysis. Hazard ratios (HRs) and associated 95\% confidence intervals were extracted from identified studies. The primary outcomes were survival discrimination and prognostic value of the new staging system with respect to the 7 th edition. Results The HRs for the eighth edition staging system were found to increase steadily showing linear progression with 1.52 in IB, 1.82 in IIA, 1.97 in IIB, 2.19 in IIIA, 5.03 in IIIB, and 7.15 in IIIC compared with IA. The prognostic values of both systems were almost the same. Conclusion This study indicated that the survival discrimination of the eighth edition of the TNM classification is valid but its prognostic ability needs further evaluation.

\section{Introduction}

Lung cancer is the leading cause of cancer related death with only second to prostate and breast cancer in terms of incidence. Lung cancer death rates have declined in the past decade but the 5 year survival still remains abysmal. ${ }^{1,2}$ Staging at the time of diagnosis is the most important predictor of survival and is a crucial part of lung cancer patient management. The $7^{\text {th }}$ edition of TNM staging was published in 2009 based on datasets that were not meant for TNM staging and not all descriptors being validated. ${ }^{3}$ The $8^{\text {th }}$ staging was released in 2017 with main changes related to tumor size, the extent of involvement, and sub-classification of extra-thoracic metastases. ${ }^{4}$ (Table 1 ) Investigators have tried to validate the new staging and obtained paradoxical results. ${ }^{5-16}$ This meta-analysis of studies is aimed to evaluate the efficacy of the new staging system with respect to the $7^{\text {th }}$ edition.

\section{Methods}

\section{Search strategy and selection criteria:}

PubMed, Embase, Web of Science, and CBM databases were searched by using combinations of the following keywords: "lung cancer," lung carcinoma," "carcinoma of lung," "lung neoplasms," "TNM classification," "TNM stage," "TNM system," "prognostic," and "prognosis" (last updated on October 31, 2018). The referenced literature in the identified reports was also retrieved for other potentially important researches. All researches were carefully estimated to identify repeated data. Criteria used to define duplicate data included study period, hospital, treatment information, and any additional inclusion criteria. No language restrictions were applied. To be included in the meta-analysis of all-cause mortality, eligibility criteria were as follows: overall survival curves generated from individual patient data, hazard ratios (HRs) could be calculated from the outcomes. Only NSCLC were included in the analysis.

\section{Data extraction and quality assessment:}


Data retrieved from the reports included publication details and study characteristics, such as sample size, median follow-up, and outcome measures.

\section{Statistical analysis}

The HRs and their variances were directly extracted from the articles or estimated indirectly from the number of events and the survival curves. ${ }^{17}$ Meta-analyses were performed using Comprehensive Metaanalysis (CMA) software version 3 (Biostat, NJ, USA) when there was more than one study. A fixed-effect model with the method of Mantel-Haenszel 9 was used when there is no evidence of heterogeneity between studies, otherwise, a random-effects model with the method of DerSiomonian and Laird was chosen. Heterogeneity between studies was evaluated using the $Q$ statistic and $\mathrm{I}^{2}$ test which describes the percentage of variability in the effect estimates that is because of heterogeneity beyond sampling error. ${ }^{18,19}$ To evaluate the presence of publication bias, we performed Begg's funnel plot 12 and Egger's regression test. ${ }^{20-22}$ If the publication bias was found, the trim and fill method of Duvall and Tweedie was performed by adding studies that appeared to be missing to enhance the symmetry. ${ }^{23,24}$ The adjusted pooled effect size and its $95 \%$ Confidence Interval $(\mathrm{Cl})$ were computed after the addition of potential missing studies.

\section{Results}

\section{Characteristics of the studies}

After a thorough search, twelve studies were included in the detailed evaluation. Of those, four studies did not provide sufficient information to calculate HRs, even after extracting data from the graphs. ${ }^{7,8,15,16}$ of twelve studies, eight studies were eligible for analysis. Males represented $58.4 \%$ of all studies with a total of 654,185 patients. The average age was 63 years' old and the mean follow up duration was 90 months for all patients. The main characteristics of the patients and studies included were listed in Table 2.

\section{Survival discrimination by TNM staging group}

Overall survival results of TNM parameter are based on 337,198 patients for the $8^{\text {th }}$ staging system and 3,861 for the $7^{\text {th }}$ staging system with a median follow-up of 84 months. The pooled HRs of each $8^{\text {th }}$ edition TNM classification showed linear progression with 1.52 in IB, 1.82 in IIA, 1.97 in IIB, 2.19 in IIIA, 5.03 in IIIB, and 7.15 in IIIC compared with IA. On the other hand, pooled HRs of each 7th edition TNM classification were 1.36 in IB, 1.88 in IIA, 1.89 in IIB, 1.50 in IIIA and 3.45 in IIIB compared with IA (Figure 1).

In the same context, heterogeneity was observed in almost all analyses mostly due to different populations and sample sizes included. Nevertheless, no publication bias was observed using egger's regression test. The summary of the different parameters presented in Table 3.

\section{Assessment of prognostic value using C-index}


Four studies assessed the prognostic values of staging systems using C-index. The prognostic values of both systems were almost the same with a slight superiority for the $8^{\text {th }}$ system. The mean values were 0.688 and 0.690 for the $7^{\text {th }}$ and the $8^{\text {th }}$ staging systems, respectively (Figure 2 ).

\section{Discussion}

Staging of cancer is designed to provide prognosis and treatment framework. It should be able to provide meaningful comparisons between different treatment modalities and the same treatment modality between different investigators. The AJCC has published the eighth edition of TNM classification of lung cancer which has adopted several newer modifications based on the database collected between 1999 and 2010 from 16 different countries and 35 sources. $^{4}$

This edition has assimilated certain new descriptors including 23 non-anatomical elements viz. patient related elements such as smoking and demographics, tumor related factors such as standard uptake value (SUV) on PET for T and N, grade of tumor and environment related factors. ${ }^{25}$ The new staging system has been analyzed in both eastern and western countries and drew inconclusive results. This meta-analysis was done to evaluate the new classification.

With respect to the survival discrimination, the eighth edition seemed to fare better than the seventh edition. In this study, the HR for each 7th edition TNM classification were 1.36 in IB, 1.88 in IIA, 1.89 in IIB, 1.50 in IIIA and 3.45 in IIIB compared with IA. HRs for the seventh edition was found to be showing an erratic pattern. On the other hand, HRs of each 8th edition TNM classification showed linear progression with 1.52 in IB, 1.82 in IIA, 1.97 in IIB, 2.19 in IIIA, 5.03 in IIIB, and 7.15 in IIIC compared with IA. It showed a steady and reasonable increase in HRs signifying a better ability to characterize disease according to its survival curve.

Sensitivity analysis indicated that heterogeneity owing to different sample size and population. It might also be attributed to widespread lung cancer screening program mostly in western population with an earlier presentation than the eastern studies.

Most of the validation studies included in the analysis have fared toward a clear prognostic advantage towards the eighth edition individually but the meta-analysis based on four studies showed almost similar prognostic value with only slight superiority to the new edition. ${ }^{5,12-14}$ (C-index 0.688 vs 0.690 )

The new edition has finessed a number of issues which were lacking in the previous edition. It allowed the evaluation of several descriptors that is expected to help stratify patients and prognosis more accurately. It also promotes the importance of multidisciplinary meetings as a standard of practice. This is the first time when characterization of sub-solid nodules and multiple pulmonary nodules has been clarified with a distinct role of difference in clinical, radiological and pathological staging. ${ }^{26}$

Even though this edition has incorporated some of the vital components as per the advent of scientific innovations, but still has several limitations. One of the major drawbacks is that a lot of data collected 
was still not necessarily designed for TNM classification similar to its predecessor. This leads to a lack of necessary details and clarifications required for a specific descriptor. One of those descriptors is lymphangitis carcinomatosis which has still not found its place in the classification due to lack of representation in the dataset. Agencies like NCCN and American College of Chest Physicians have recommended PET scan for the initial characterization of clinically indeterminate pulmonary nodule > $8 \mathrm{~mm}$ with a probability of malignancy (5-65\%) as well as for pretreatment evaluation of lung cancer but SUV uptake of individual tumors have not been included in the stage. ${ }^{27,28}$ Modern medicine has evolved from radical to a more personalized way of treating cancer. Some of the malignancies have incorporated methods of precision medicine into its staging system such as breast cancer in the recent update but lung cancer staging has still not incorporated factors like immunohistochemistry and mutation genetics e.g. EGFR which can impact on treatment response and outcome. ${ }^{29}$

Like its predecessor, the eighth edition has been marred by the lack of representation of patients who were treated other than surgery. ( $12 \%$ to $4.7 \%$ ) Owing to that generalizability of the new staging system for nonsurgical treatment modalities might affect the prognostic impact of the TNM descriptors. ${ }^{30}$ This meta-analysis has taken that into consideration with the incorporation of validation studies which have used radiotherapy and chemotherapy as their treatment modalities and came to the conclusion that prognostic ability of the new stage is almost same as its predecessor. The validity of the prognostic ability of the staging system is under scrutiny and should be further investigated.

In conclusion, the application of the eighth edition of the TNM classification in survival discrimination is valid but the prediction of prognosis needs further evaluation. The future staging system should be based on the dataset which is designed for TNM classification with the incorporation of elements of precision medicine and more representation of non-surgically treated patients.

\section{Clinical Practice Points}

AJCC staging system for lung cancer was first devised in year 1977. Since then there has been eight editions which has refined various aspect so that there is minimal distinction between the data and the reality. Each new edition of staging system is designed with respect to the drawbacks of the previous editions. External validation studies have evaluated the efficacy of the new stage and have found paradoxical results. The meta-analysis of such 8 validation studies showed a better survival discriminatory ability of $8^{\text {th }}$ edition but the prognostic ability is similar between the two staging system. This study validates the new stage but also has highlighted important aspects which should be taken into consideration for the upcoming editions such TNM classification based data set, more representation of non-surgically treated patients. The role of Lymphangitis carcinomatosis should be addressed. We have come a long way in terms of refining the staging system but there is still a long way to go.

\section{Declarations}


Acknowledgment: Author would like to thank Dr. Mikael Hartman for his technical advice and Prof. SVS Deo for his guidance.

Funding: This research did not receive any specific grant from funding agencies in the public, commercial, or not-for-profit sectors.

\section{Conflicts of interest: none}

Informed consent: Relevant informed consent has been taken for the research.

Availability of Data and Materials: Author wishes to share the data and supplementary material associated with this research.

\section{References}

1. Siegel RL, Miller KD, Jemal A. Cancer statistics, 2018. CA Cancer J Clin. 2018;68(1):7-30.

2. Jemal A, Thun MJ, Ries LAG, Howe HL, Weir HK, Center MM, et al. Annual report to the nation on the status of cancer, 1975-2005, featuring trends in lung cancer, tobacco use, and tobacco control. J Natl Cancer Inst. 2008;100(23):1672-94.

3. Rami-Porta R, Goldstraw P. Strength, and weakness of the new TNM classification for lung cancer. Eur Respir J. 2010;36(2):237-9.

4. Amin, M.B., Edge, S., Greene, F., Byrd, D.R., Brookland, R.K., Washington, M.K., Gershenwald, J.E., Compton, C.C., Hess, K.R., Sullivan, D.C., Jessup, J.M., Brierley, J.D., Gaspar, L.E., Schilsky, R.L., Balch, C.M., Winchester, D.P., Asare, E.A., Madera, LR. AJCC Cancer Staging Manual (8th edition). Springer International Publishing; 2017.

5. Yang L, Wang S, Zhou Y, Lai S, Xiao G, Gazdar A, et al. Evaluation of the 7th and 8th editions of the AJCC/UICC TNM staging systems for lung cancer in a large North American cohort. Oncotarget. 2017;8(40):66784-95.

6. Koul R, Rathod S, Dubey A, Bashir B, Chowdhury A. Comparison of 7th and 8th editions of the UICC/AJCC TNM staging for non-small cell lung cancer in a non-metastatic North American cohort undergoing primary radiation treatment. Lung Cancer 2018 Sep 1;123:116-20.

7. Abdel-Rahman 0 . Validation of the prognostic value of new sub-stages within the AJCC 8th edition of non-small cell lung cancer. Clin Transl Oncol. 2017;19(11):1414-20.

8. Chen K, Chen H, Yang F, Sui X, Li X, Wang J. Validation of the Eighth Edition of the TNM Staging System for Lung Cancer in 2043 Surgically Treated Patients With Non-small-cell Lung Cancer. Clin Lung Cancer. 2017;18(6):e457-66.

9. Sui X, Jiang W, Chen H, Yang F, Wang J, Wang Q. Validation of the Stage Groupings in the Eighth Edition of the TNM Classification for Lung Cancer. J Thorac Oncol. 2017;12(11):1679-86.

10. Aokage K, Miyoshi T, Ishii G, Kusumoto M, Nomura S, Katsumata S, et al. Clinical and Pathological Staging Validation in the Eighth Edition of the TNM Classification for Lung Cancer: Correlation 
between Solid Size on Thin-Section Computed Tomography and Invasive Size in Pathological Findings in the New T Classification. J Thorac Oncol. 2017;12(9):1403-12.

11. Chansky K, Detterbeck FC, Nicholson AG, Rusch VW, Vallières E, Groome P, et al. The IASLC Lung Cancer Staging Project: External Validation of the Revision of the TNM Stage Groupings in the Eighth Edition of the TNM Classification of Lung Cancer. J Thorac Oncol. 2017;12(7):1109-21.

12. Jung HS, Lee JG, Lee CY, Kim DJ, Chung KY. Validation of the T descriptor in the new 8th TNM classification for non-small cell lung cancer. J Thorac Dis. 2018;10(1):162-7.

13. Li J, Yang X, Xia T, Guan Y, Zhong N. Stage I synchronous multiple primary non-small cell lung cancer: CT findings and the effect of TNM staging with the 7th and 8th editions on prognosis. $J$ Thorac Dis. 2017;9(12):5335-44.

14. Yin N, Ha M, Liu Y, Gu H, Zhang Z, Liu W. Prognostic significance of subclassification of stage IIB lung cancer: a retrospective study of 226 patients. Oncotarget. 2017;8(28):45777-83.

15. Jin Y, Chen M, Yu X. Comparison of the 7 th and proposed 8 th editions of the AJCC/UICC TNM staging system for non-small cell lung cancer undergoing radical surgery. Sci Rep. 2016;6(May):611.

16. Shin JY, Yoon JK, Marwaha G. External Validation of the New International Association for the Study of Lung Cancer Tumor, Node, and Metastasis 8th Edition Staging System and Updated T Descriptors in Determining Prognosis for Patients With Non-Small Cell Lung Cancer Patients With N3 D. Clin Lung Cancer. 2017;18(6):e481-9.

17. Tierney JF, Stewart LA, Ghersi D, Burdett S, Sydes MR. Practical methods for incorporating summary time-to-event data into metaanalysis. Trials. 2007;8:16.

18. DerSimonian R, Laird N. Meta-analysis in clinical trials. Control Clin Trials. 1986;7(3):177-188.

19. Higgins JPT, Thompson SG, Deeks JJ, Altman DG. Measuring inconsistency in meta-analyses. BMJ. 2003;327(7414):557-560.

20. Begg CB, Mazumdar M. Operating characteristics of a rank correlation test for publication bias. Biometrics. 1994;50(4):1088-1101.

21. Peters JL, Sutton AJ, Jones DR, Abrams KR, Rushton L. Comparison of two methods to detect publication bias in meta-analysis. JAMA. 2006;295(6):676-680.

22. Egger M, Davey Smith G, Schneider M, Minder C. Bias in meta-analysis detected by a simple, graphical test. BMJ. 1997;315(7109):629-634.

23. Duval S, Tweedie R. Trim and fill: A simple funnel-plot-based method of testing and adjusting for publication bias in meta-analysis. Biometrics. 2000;56(2):455-463.

24. Thompson SG, Higgins JPT. How should meta-regression analyses be undertaken and interpreted? Stat Med. 2002;21(11):1559-1573.

25. Rami-Porta R, Bolejack V, Giroux DJ, Chansky K, Crowley J, Asamura H, et al. The IASLC lung cancer staging project: The new database to inform the eighth edition of the TNM classification of lung cancer. J Thorac Oncol. 2014;9(11):1618-24. 
26. Rami-Porta R, Asamura H, Travis WD, Rusch VW. Lung cancer - major changes in the American Joint Committee on Cancer eighth edition cancer staging manual. CA Cancer J Clin. 2017;67(2):138-55.

27. National Comprehensive Cancer Network (NCCN). NCCN Clinical Practice Guidelines in Oncology. Non-Small Cell Lung Cancer (Version 1.2019). 2019 Jan 1; National Comprehensive Cancer Network. Available from: https://www.nccn.org/professionals/physician_gls/pdf/nscl.pdf

28. Gould MK, Donington J, Lynch WR, Mazzone PJ, Midthun DE, Naidich DP, et al. Evaluation of individuals with pulmonary nodules: When is it lung cancer? Diagnosis and management of lung cancer, 3rd ed: American college of chest physicians evidence-based clinical practice guidelines. Chest. 2013;143(5 SUPPL):e93S-e120S.

29. National Comprehensive Cancer Network (NCCN). NCCN Clinical Practice Guidelines in Oncology. Breast Cancer (Version 3.2018). 2019 Jan 1; National Comprehensive Cancer Network Available from: https://www.nccn.org/professionals/physician_gls/pdf/breast.pdf

30. Choi HS, Jeong BK, Jeong H, Lee YH, Ha IB, Song JH, et al. Application of the new 8th TNM staging system for non-small cell lung cancer: Treated with curative concurrent chemoradiotherapy. Radiat Oncol. 2017;12(1):1-8

\section{Tables}

Table 1: Key features distinguishing the eighth edition classification 


\begin{tabular}{|c|c|c|c|}
\hline & Descriptors & $7^{\text {th }}$ edition & $8^{\text {th }}$ edition \\
\hline \multirow[t]{5}{*}{ Tumor Size } & $>1-\leq 2 \mathrm{~cm}$ & T1a & $\mathrm{T} 1 \mathrm{~b}$ \\
\hline & $>2-\leq 3 \mathrm{~cm}$ & $\mathrm{~T} 1 \mathrm{~b}$ & $\mathrm{~T} 1 \mathrm{c}$ \\
\hline & $>4-\leq 5 \mathrm{~cm}$ & $\mathrm{~T} 2 \mathrm{a}$ & $\mathrm{T} 2 \mathrm{~b}$ \\
\hline & $>5-\leq 7 \mathrm{~cm}$ & $\mathrm{~T} 2 \mathrm{~b}$ & $\mathrm{~T} 3$ \\
\hline & $>7 \mathrm{~cm}$ & T3 & $\mathrm{T} 4$ \\
\hline Tumor & Within main bronchus $<2 \mathrm{~cm}$ of & T3 & $\mathrm{T} 2$ \\
\hline \multirow[t]{4}{*}{ Descriptor } & carina & & \\
\hline & Obstructive atelectasis (whole & T3 & $\mathrm{T} 2$ \\
\hline & lung) & & \\
\hline & Local invasion of Diaphragm & T3 & $\mathrm{T} 4$ \\
\hline \multirow[t]{3}{*}{ Metastases } & M1b & Distant & Single extrathoracic metastasis or involvement of a single distant (non- \\
\hline & & metastasis & regional) node \\
\hline & M1c & & Multiple extrathoracic metastases in one or several organs \\
\hline
\end{tabular}

Table 2: Study characteristics 


\begin{tabular}{|c|c|c|c|c|c|c|}
\hline Study by first author & Year & Country & No. of Patients & Males; N (\%) & Age; Mean \pm SD & Time frame \\
\hline $\mathrm{Koul}^{10}$ & 2018 & Canada & 295 & $150(50.9)$ & $71.8 \pm 14.2$ & January 2011 to December 2014 \\
\hline Abdel-Rahman ${ }^{5}$ & 2017 & Egypt & 127,096 & $66,353(52.2)$ & - & 2010 to 2013 \\
\hline Aokage $^{6}$ & 2017 & Japan & 1792 & $1,155(64)$ & $66 \pm 9$ & January 2003 to December 2011 \\
\hline Chansky $^{9}$ & 2017 & USA & 982,647 & $577305(58.7)$ & - & $1999-2010$ and 2000-2012 \\
\hline Chen $^{12}$ & 2017 & China & 2,043 & $1,109(54.3)$ & $62 \pm 11.9$ & January 2006 to September 2015 \\
\hline Jung $^{13}$ & 2017 & Korea & 1,316 & $816(62.0)$ & $63.1 \pm 0.3$ & January 1999 to December 2012 \\
\hline Sui $^{11}$ & 2017 & China & 3,929 & $2279(63.3)$ & $58 \pm 3.7$ & January 2005 to December 2012 \\
\hline Yang $^{14}$ & 2017 & USA & 858,909 & - & - & 2004 to 2013 \\
\hline
\end{tabular}

Table 3: Hazard ratios and $95 \%$ confidence intervals ( $95 \% \mathrm{CI}$ ) for survival by stage (vs. IA) 


\begin{tabular}{|c|c|c|c|c|c|c|c|c|}
\hline Stage & System & No. of patients & HRs & 95\% LCI & $95 \%$ UCI & P-value & $\mathrm{I}^{2}(\%)$ & Egger's P-value \\
\hline \multirow[t]{2}{*}{ IB } & 7th & 600 & 1.36 & 0.85 & 2.18 & 0.198 & 91.01 & 0.746 \\
\hline & 8th & 5,674 & 1.52 & 1.06 & 2.16 & 0.003 & 94.88 & 0.343 \\
\hline \multirow[t]{2}{*}{ IIA } & 7th & 1,786 & 1.88 & 0.88 & 4.03 & 0.106 & 95.19 & 0.741 \\
\hline & 8th & 13,908 & 1.82 & 1.16 & 2.86 & 0.006 & 96.01 & 0.268 \\
\hline \multirow[t]{2}{*}{ IIB } & 7th & 393 & 1.89 & 0.70 & 5.12 & 0.210 & 96.35 & 0.919 \\
\hline & 8th & 119,111 & 1.97 & 1.10 & 3.54 & 0.785 & 99.91 & 0.168 \\
\hline \multirow[t]{2}{*}{ IIIA } & 7th & 1,004 & 1.50 & 0.37 & 6.12 & 0.570 & 98.47 & 0.521 \\
\hline & 8th & 79,988 & 2.19 & 0.82 & 5.86 & 0.037 & 99.67 & 0.461 \\
\hline \multirow[t]{2}{*}{ IIIB } & 7th & 78 & 3.45 & 2.24 & 5.31 & $<0.001$ & 0.00 & 0.289 \\
\hline & 8th & 74,631 & 5.03 & 3.46 & 7.31 & $<0.001$ & 99.68 & 0.289 \\
\hline \multirow[t]{2}{*}{ IIIC } & 7th & - & & & & & & \\
\hline & 8th & 19,196 & 7.15 & 3.33 & 14.38 & 0.001 & 99.80 & 0.401 \\
\hline
\end{tabular}

Figures 


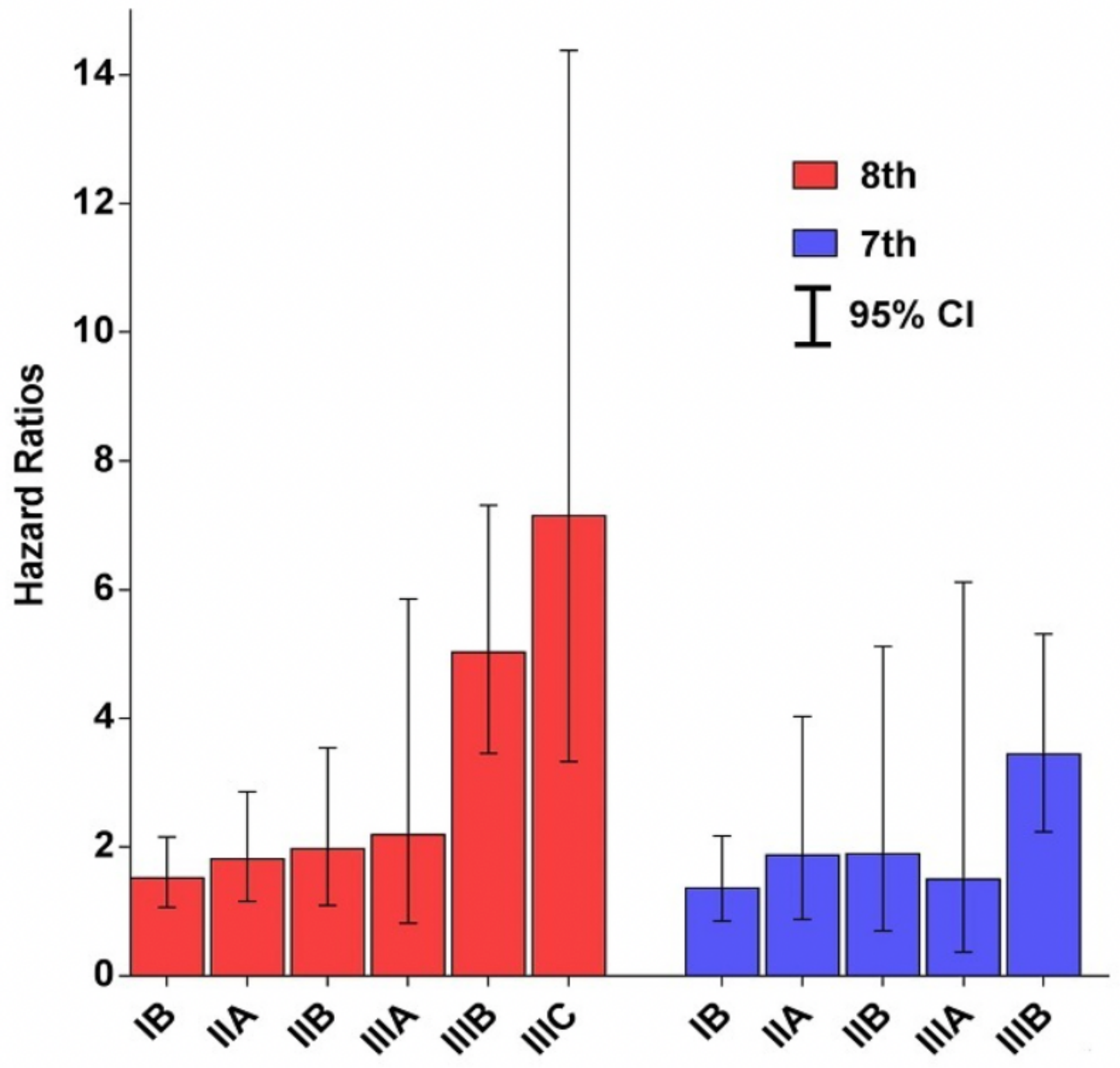

Figure 1

Hazard ratios for survival by 8th and 7th AJCC TNM stage (vs. stage IA). Error bars represent $95 \%$ confidence intervals. 


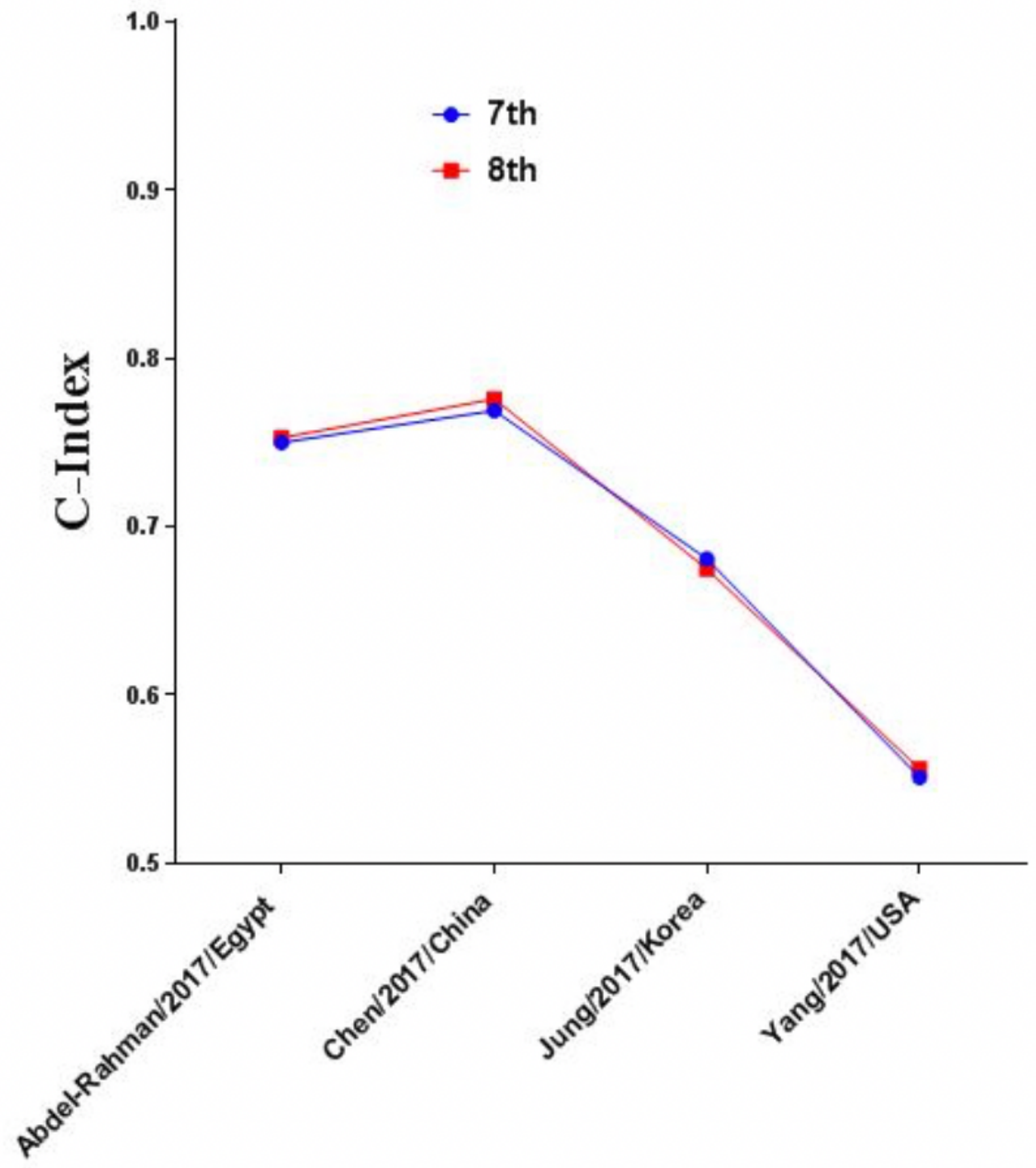

Figure 2

Summary of C-index for 8th and 7th AJCC TNM stage.

\section{Supplementary Files}

This is a list of supplementary files associated with this preprint. Click to download. 
- Appendix.docx

Page 14/14 